\title{
A STUDY ON PLASTIC HINGE FORMATION IN RC FRAME BY NONLINEAR STATIC ANALYSIS
}

\author{
Ravikumara H S ${ }^{1}$, Supriya R Kulkarni ${ }^{2}$, K S Babu Narayan ${ }^{3}$ \\ ${ }^{1}$ Research Scholars, Department of Civil Engineering, NITK, Surathkal, India. \\ ${ }^{2}$ Research Scholars, Department of Civil Engineering, NITK, Surathkal, India. \\ ${ }^{3}$ Professor, Department of Civil Engineering, NITK, Surathkal, India. \\ Mail(ID):ravikumarhs_92@yahoo.co.in
}

\begin{abstract}
The design of effective structural system configured with all seismic performance objectives ranging from serviceability considerations to life safety and collapse prevention is the most important part of Seismic design. For seismic performance evaluation of structures, the static push over analysis which provides adequate information on seismic demands imposed by the ground motion has been popularized in recent decades. This evaluates the expected performance of a structure by estimating its strength and deformation demands to design ground motions by means of static inelastic analysis. The evaluation considers the factors such as global drift, interstorey drift, inelastic element deformations, deformation between elements etc. The first and most important step of this procedure, modeling of the structure demands the determination of the nonlinear properties of each component that are quantified by strength and deformation capacities. The factors that affect the ultimate deformation capacity of a structure also depends on the ultimate curvature and plastic hinge properties. The effect of plastic hinge properties in nonlinear analysis has been studied by many researchers. However, a little or negligible attention has given to understand the sequence of hinge formation and its effect. An attempt has been made in this paper to understand the order of hinge formation for ground motions and thereby tried to enhance the accuracy of push over analysis. A single bay single storied RC frame has been analyzed by using the software package SAP 2000 and hinges formed were observed with their order and location and results have been discussed.
\end{abstract}

Keywords: Push over Analysis, interstorey drift, Plastic hinge, nonlinear properties and SAP 2000.

\section{INTRODUCTION}

The seismic design demands the structural system configured with seismic performance objectives ranging from serviceability considerations to life safety and collapse prevention. It is also needed to create mathematical models or physical models to evaluate the seismic performance of an existing system and to modify the component behaviour characteristics such as strength, stiffness and deformation capacity to better suit the desired performance criteria.

Push over analysis has been substantially popularised in recent decades as a tool to evaluate the expected performance of a structural system by estimating its strength and deformation demands in designing earthquake resistant buildings by means of static inelastic analysis.

\subsection{Problem Description}

Many researchers have tried to recognise the shortcomings and pitfalls of Push over analysis in last four decades. Notwithstanding the models proposed to match the analytical results to that of experiment, it is still struggling to observe the deformation characteristics similar to that of experiments. A thorough investigation has not yet been carried out to address this issue.
Therefore, an attempt has been made in this paper to understand the order of sequence of hinge formation which may be the possible reason for the above mentioned issue.

\subsection{Objectives}

There are various parameters which affects the deformation characteristics in push over analysis such as material properties, geometries, plastic hinge length etc. The plastic hinges which forms during the performance of a structure under ground motions is also an important factor which affects the deformation characteristics of the structure .The order of hinge formation and their effect has been tried to observe by modelling and analysing a simple single bay single storied RC frame using a software package SAP 2000 .

The results were tabulated for each and every plastic hinge formed with their order and observations were discussed.

\subsection{Modelling of RC frame}

A simplified model of a single bay single storey frame is considered for the analysis.

The frame has the height of $3.2 \mathrm{~m}$ and width of $2.4 \mathrm{~m}$. The beam has the dimension of $115 \mathrm{mmX} 230 \mathrm{~mm}$ and that of columns is $115 \mathrm{mmX} 250 \mathrm{~mm}$. The Joints were fixed and the reinforments provided is as shown in the figure 1. 


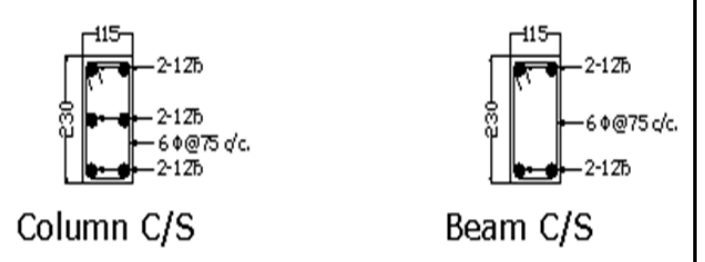

Figure 1. Details of size and reinforcement of Beam and Column.

Dimensions and Properties of Frame Section are shown in the Table 1.

Table 1. Member section Properties

\begin{tabular}{||c|c|c|c||}
\hline \hline Member & $\begin{array}{c}\text { Diameter } \\
\text { of bar }\end{array}$ & $\begin{array}{c}\text { Number } \\
\text { of Bars }\end{array}$ & Cross-section \\
\hline Column & $12 \mathrm{~mm}$ & 6 & $115 \mathrm{~mm} \times 230 \mathrm{~mm}$ \\
\hline Beam & $12 \mathrm{~mm}$ & 4 & $115 \mathrm{~mm} \times 250 \mathrm{~mm}$ \\
\hline
\end{tabular}

The RC frame model with above mentioned materials and dimension has been modeled by using SAP 2000. The default hinge properties included in this program are based on ATC 40 and FEMA 273 guidelines. The user defined option has been used here and moment curvature analysis has been done using compatibility and equilibrium equations.Lateral load distribution across the height of the frame is found out by using the formula specified in FEMA 356 , given by equation below and then in-cooperated in the model.

$F_{x}=\frac{W_{x} h_{x}^{k}}{\sum_{i=0}^{N} W_{i} h_{i}^{k}} V$

$C_{v x}=\frac{W_{x} h_{x}^{k}}{\sum_{i=0}^{N} W_{i} h_{i}^{k}}$

Fx is the applied lateral force at level ' $\mathrm{x}$ ', $\mathrm{W}$ is the storey weight, $\mathrm{h}$ is the story height, $\mathrm{V}$ is the design base shear and $\mathrm{N}$ is the number of stories. $\mathrm{C}_{\mathrm{vx}}$ is the coefficient that represents the lateral load multiplication factor to be applied at floor level ' $\mathrm{x}$ '. The load pattern for tests was kept as parabolic with the load value at a storey increasing in proportion to the square of the height of the floor from foundation level.

We have,

Height of floor from foundation level,

$\mathrm{h} 1=3200 \mathrm{~mm}$

$\Sigma \mathrm{hi}^{2}=10240000$

Weightage of total force for 1 st floor,

$\mathrm{h}^{2} / \Sigma \mathrm{hi}^{2}=1$.

By using the values calculated above Push over analysis has been carried out.

\subsection{Push over Analysis}

Push over analysis using SAP2000 include the implementation of FEMA 356 and the hinge option based on stress - strain. It has been used worldwide due to its simple nature. It estimates the capacity, demand and performance of the structure underground motions. The capacity of the structure to withstand the incremental lateral loading, target displacement can be symbolized by Capacity curve and Demand respectively. By knowing the capacity and demand of a certain structure, the performance of the structure can be found out on the basis global and component accepted deformations.

Like other factors which affect the target displacement, the plastic hinges that forms in the structure have their own importance. Therefore it is necessary to understand the sequence of hinge formation during ground motions. This research work tried to address the issue related to behavior of the structure under the order of hinge formation. The Change in push over curve at every hinge formed has been observed and tabulated as below.

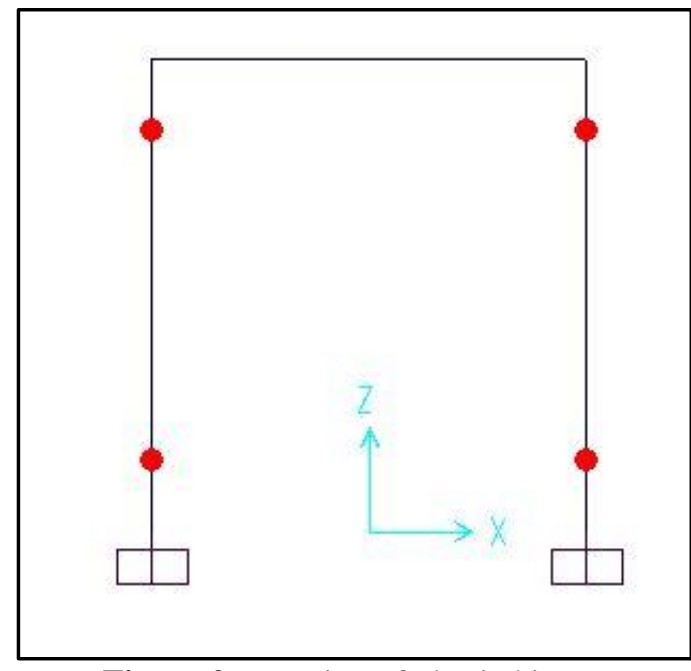

Figure 2. Location of plastic hinges

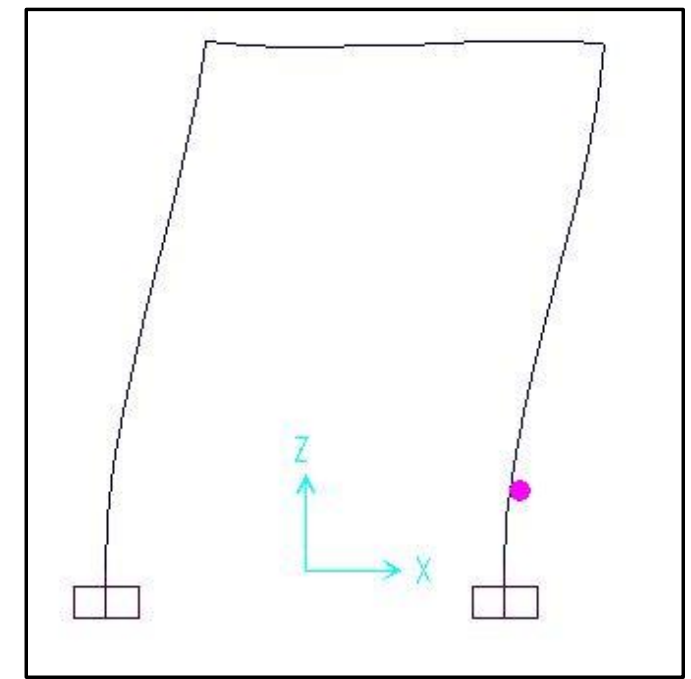

Figure 3. Formation of first hinge and its location 
Figure 2 shows the location and number hinges formed .There are four hinges which shows the performance of the frame to ground motions. The location of first and second hinges with their order and location are shown in figures 3 and 4 respectively. The analysis shows the third and fourth hinges formed simultaneously and it is same as figure 2 .

After completing the analysis the push over curve obtained is extracted from SAP 2000 as shown in figure 5.

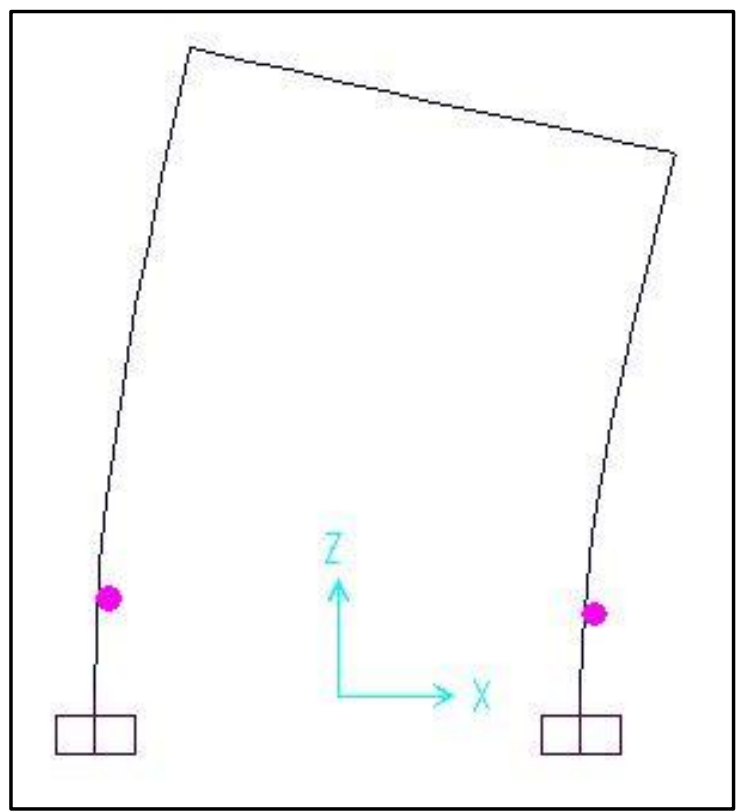

Figure 4 . Second hinge formation and deformed shape of the frame

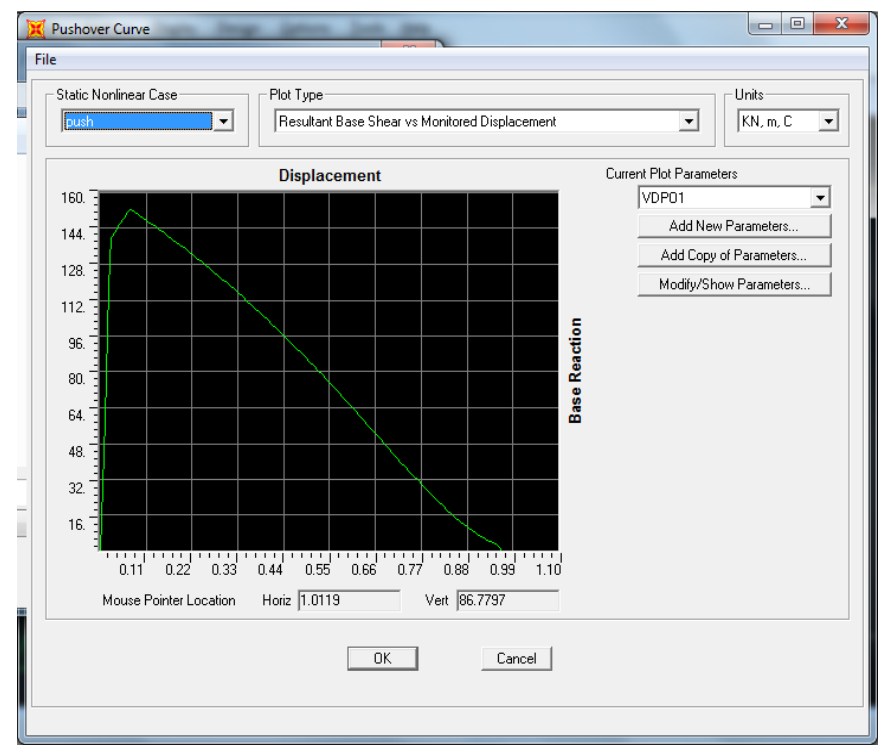

Figure 5. Push over curve from SAP 2000

\subsection{Results and Discussions}

The results obtained from Push over analysis have been tabulated in the table 2 and push over curve i.e Base shear v/s Displacement curve for the same has been plotted as shown in the figure 6 .
Table 2. Displacement w.r.t Base force

\begin{tabular}{|l|l|}
\hline Displacement & Base Force \\
\hline $\mathrm{m}$ & $\mathrm{KN}$ \\
\hline 0.00000407 & 0 \\
\hline 0.010004 & 58.742 \\
\hline 0.055961 & 148.563 \\
\hline 0.10324 & 148.526 \\
\hline 0.15324 & 141.851 \\
\hline 0.20324 & 134.822 \\
\hline 0.25324 & 127.421 \\
\hline 0.30324 & 119.628 \\
\hline 0.35324 & 111.427 \\
\hline 0.40324 & 102.808 \\
\hline 0.45324 & 93.766 \\
\hline 0.50324 & 84.313 \\
\hline 0.55324 & 74.475 \\
\hline 0.60324 & 64.31 \\
\hline
\end{tabular}

It can be observed from the table that the maximum Base force of $148.526 \mathrm{kN}$ is observed at the displacement of $0.103 \mathrm{~m}$ where the frame has been reached its maximum capacity and minimum displacement. The base force which caused the maximum displacement of $0.603 \mathrm{~m}$ is as less as 64.31. The same observation can be seen from the figure 6 . The figure 6 represents the curve w.r.t four hinges (figure 2) formed during push over analysis. The target displacement of $0.60324 \mathrm{~m}$ observed at $106^{\text {th }}$ step of incremental displacement controlled push over analysis. The first hinge formed at $12^{\text {th }}$ step at the location as shown in the figure 3 and corresponding base shear and displacement are $58.742 \mathrm{kN}$ and $0.010004 \mathrm{~m}$ respectively.However , the second hinge which has been shown in figure 4 . has been formed at $213^{\text {th }}$ step of incremental displacement controlled push over analysis and respective base shear and displacement were $127.421 \mathrm{kN}$ and $0.25324 \mathrm{~m}$.

The above observation clearly shows that sequence of hinge formation has notable effect on deformation characteristics of the frame which can be observed by carefully assigning the displacements in increments.

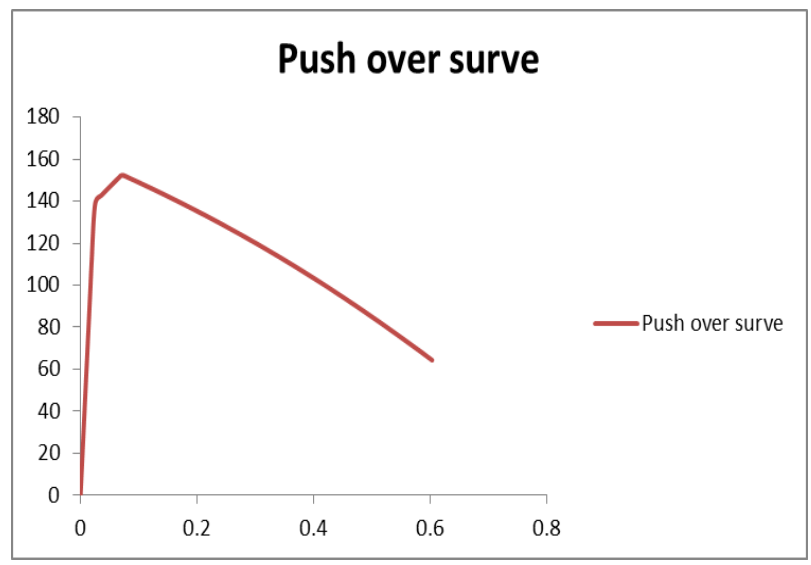

Figure 6. Push over curve 


\subsection{CONCLUSIONS}

Though the attempt needs much more understanding of the hinge sequence, the following conclusions can be made on the work carried out in this research.

- The Location of plastic hinge can vary according to the geometrical properties of structural components.

- The order of sequence of hinge formation controls the deformation characteristics of the structures.

- The gap between the successive hinge formation has a lot of role in the behavior of the structure.

- The Performance of the structure under ground motion can be understood in much better way if the hinge formation and corresponding displacement characteristics is observed.

\section{REFERENCES}

[1] Applied Technology Council, ATC-40.Seismic evaluation and retrofit of concrete .

[2] CP 110: PART 1:1972- British code of practice.

[3] CSI, SAP2000 Integrated finite element analysis and design of structures basic analysis reference manual, Berkeley (CA,USA): Computers and Structures,2002. Computers and Structures.

[4] Federal Emergency Management Agency, FEMA273.NEHRP guideline for Seismic rehabilitation of buildings Washington (DC); 1997.

[6] NeenaPanandikar (Hede), Babu Narayan K.S, "Stochastic analysis for assessment of Sensitivity of pushover curve to design parameters", International Journal of Innovations in Engineering and Technology (IJIET), Vol. 3 Issue 4 April 2014.

[6]G. Tarţa and a. Pintea, "Seismic Evaluation of MultiStorey Moment-Resisting Steel Frames With Stiffness Irregularities Using Standard and Advanced Pushover Methods," Procedia Eng., vol. 40, pp. 445-450, 2012.

[7] H. Krawinkler and G. D. P. K. Seneviratna, "Pros and cons of a pushover analysis of seismic performance evaluation," Eng. Struct., vol. 20, no. 4-6, pp. 452-464, 1998. 